\begin{tabular}{|c|c|}
\hline Journal of Association of Arab Universities \\
for Tourism and Hospitality (JAAUTH) \\
Vol. 19 No. 2, (2020), pp.227-257. \\
journal homepage: http://jaauth.journals.ekb.eg
\end{tabular}

\title{
Factors Influencing Customers' Behavior toward Eating Healthy Food in Restaurants at Minia Governorate in Egypt
}

\author{
Mostafa M. M. Hussein \\ Lecturer at Hotel Management Department, Faculty of Tourism and Hotels, Minia \\ University, Egypt.
}

\section{ARTICLE INFO}

Keywords:

Menu calorie labeling;

Healthy food; Theory of planned behavior,

Behavioral intentions, Customer behavior.

\begin{abstract}
The research aimed to examine the factors influencing customers' behavior towards eating healthy food at Minia district restaurants in Minia governorate in Egypt. The research used a quantitative approach and conducted descriptive-analytical methodology by using a questionnaire. The inhabitants of Minia district were the population of the research who visit 52 main restaurants in Minia. Five hundred questionnaires were distributed to restaurants' customers as a sample of the research, 385 returned questionnaires were valid to analyze with a response rate of $77 \%$ of distributed questionnaires. The data were analyzed using descriptive statistics, regression, T-Test, and Anova by using SPSS 22. The results showed that the averages of restaurant customers' affective attitude; injunctive and descriptive norms; perceived behavioral control; behavioral intentions; behavior were moderate, which might cause obesity and its diseases to customers. Moreover, perceived health problems of eating high-calorie foods; positive outcomes of eating healthy food; affective and cognitive attitudes; injunctive and descriptive norms; perceived behavior control had a significant influence on customers' behavioral intentions towards eating healthful food in restaurants. Customers' behavioral intention also had a significant influence on their eating healthy food behavior. There were only significant differences between customers' educational levels, where customers who got secondary school were better than those who got bachelor degree towards eating healthy behavior.
\end{abstract}

\section{Introduction}

Overweight and obesity were defined as excrescent fat cumulating that forms a health risk. The body mass index (BMI) is a simple index of weight-for-height that is used to assort underweight, overweight and obesity in people. A person with a BMI of 25 or more had deemed to be overweight, while a person with a BMI of 30 or more had considered obese (World Health Organization, 2020). In 2015, a total of 107.7 million 
children and 603.7 million adults were obese. High BMI interpreted 4.0 million deaths globally (Massachusetts Medical Society, 2017). In 2010, the proportion of Americans' food budget for Food Away From Home (FAFH) compassed 50 \% which exceeded the proportion for food at home. Likewise, Americans' proportion of energy intake from FAFH increased from $17 \%$ in 1977-78 to $34 \%$ in 2011-12. The increasing presence of FAFH in Americans' diets caused changes in customer demand and producer behavior and influenced the persons' health (Saksena et al., 2018).

Almost three-quarters of people surveyed commonly ate out at least once a week. More than half of them visited full-service and fast-food restaurants (Stewart et al., 2006). Some of the fast-food restaurants made nutritional information available in their chains, but it was not constantly obtainable, and not simple to read when it was available. Full-service restaurants seldom provided nutritional information on their menus or websites (Josiam and Foster, 2009). In the UK one in six meals was consumed outside the home, offering $25 \%$ and $20 \%$ of energy intakes for men and women, respectively. Thus, customers should aware of the nutritional content of the foods they consume. The New York City Board of Health also threaded in 2008 a law imposing many restaurants to offer nutritional information on their menus visibly. This law applied to all restaurants that belonged to a group of 15 or more businesses and provided the same items and was standardized for portion size and content (Benelam, 2009). Unilever's Food Solutions Division (2011) found that almost 90\% of people surveyed in non-Western countries and the majority in Western countries desired for nutritional information to be available when eating out to make the right choices.

Rizkallah and Feiler (2013) illustrated that obesity became a major societal problem, thus concerned parties should work together to inform, and motivate the individual to be informed of obesity problems, and bad eating habits. When achieving that, customers also pressure other parties to change their practices. Furthermore, in 2015, the highest level of obesity amongst children and young adults was at nearly $13 \%$ in the USA. Adult obesity was highest in Egypt at about 35\%. The highest numbers of obese children were in China with 15.3 million and in India with 14.4 million. The highest numbers of obese adults were in the USA with 79.4 million and China with 57.3 million in 2015. People who shrug off weight gain suffered from cardiovascular disease, diabetes, cancer, and other life-threatening conditions (Massachusetts Medical Society, 2017).

The prevalence of overweight and obesity in Egypt, Bahrain, Jordan, Kuwait, Saudi Arabia and United Arab Emirates ranged from $74 \%$ to $86 \%$ in women and $69 \%$ to $77 \%$ in men (World Health Organization, 2020). Minia Governorate population had overweight and obesity for women and men as a part of Egypt. World Bank (2017) reported that Minia governorate had seven hotels with 618 beds and hosts an estimated 63 thousand visitors yearly. Thus, the current research was applied at Minia city in Minia Governorate in Egypt. 
This research aims to examine the effects of perceived health problems of eating high-calorie food; positive outcomes of eating healthy food; affective and cognitive attitudes; injunctive and descriptive norms; perceived behavioral control on restaurants customers' behavioral intention. The influence of customers' behavioral intention on their healthy eating behavior is also examined.

\section{Literature review}

\subsection{The health problems of eating high-calorie food influence on customers' intentions of eating healthy food}

As the grades of the realized threat increased, the likelihood that conservative health behaviors were increased (Bishop et al., 2015) and the behavioral intention to require weight decrease (Park, 2011). Realized threats; benefits; barriers of using menu labels positively affected the customers' usage of menu labels. Realized threats were affected by cues to action and cues to action had an indirect influence on menu label usage through realized threats (Jeong and Ham, 2018). Therefore, the researcher suggested hypothesis one as follows:

H1. Perceived health problems of eating high-calorie food have a positive effect on the intention to eat healthy food at restaurants.

\subsection{The health outcomes of eating healthy food influence on customers' intention to eat healthy food at restaurants}

Customer intentions to select low-fat food were reinforced when they approved consuming healthy food was a way to achieve their health goals, herewith continuing healthy eating behaviors (Chen et al., 2006). Due to rising health concern, customers were willing to prevent high fat or calorie foods, even if they knew them delicious, to select healthy foods (Sualakamala and Huffman, 2010). Customers were probably to choose healthful menu items, if they found healthful foods to be tasteful or delightful. Hedonic expectancy determined the probability of eating healthful food (Saba et al., 2010). Customers selected healthful choices because of the positive results obtained from previously eating healthful foods and the knowledge they had about healthful foods (Varela et al., 2010). Health value was the key variable that inspired customer concern in healthful eating and aroused hedonic and positive result anticipations, which in turn promoted intentions to consuming healthful food items (Kang et al., 2015). Based on the discussion above, the researcher assumed hypothesis two as follows:

H2. Positive outcomes of eating healthful food (low-calories) have a positive effect on the intention to eat healthy food at restaurants.

\subsection{Theory of planned behavior}

The theory of planned behavior (TPB) was a theoretically organized framework that foresaw and demonstrated human behavior according to beliefs and attitudes (Ajzen, 1991). TPB assumed that the proximal determinant of behavior was an individual intention to execute the behavior, when three independent variables identified intention: attitude, subjective norm, and perceived behavioral control. Particular prominent beliefs that underlie behavioral, normative, and control beliefs identified all of the variables (attitude, subjective norm, and perceived behavioral control). 
Moreover, TPB was one of the major expectancy-value models employed by research to investigate behavior-related food choices and behavioral intention (Kim et al., 2013). The TPB constructs were illustrated as follows:

\subsubsection{Attitude: definition and categories}

Attitude meant an individual's mental state that reflected person's overall positive or negative appraisal of acting a specific behavior. It arose from a set of more particular, outstanding, behavioral beliefs that reflect perceived results related to the targeted behavior. (Ajzen, 1991; Zhang, 2018).

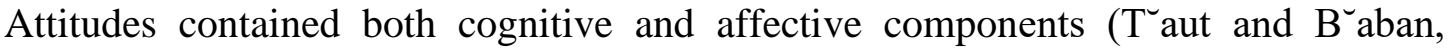
2012). The affective attitude was defined as the individual's general level of favorable or unfavorable feelings regarding the issue, whereas cognitive attitude was the person's beliefs about the instrumental usefulness of the action for the achievement or obstructing of his or her goals weighted by the value placed on such goals (Norman, 1975). Dunn et al. (2011) found that only cognitive attitudes had a significant influence on the intention to eat fast food. However, other studies had shown that affective attitude had a stronger influence than cognitive attitude on behavioral

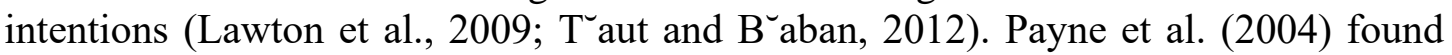
that affective attitude toward eating healthy was the most effective variable in forming intentions. Therefore, the researcher, supposed the third and fourth hypotheses as follows:

H3. Affective attitude toward eating healthful food (low-calories) has a positive effect on the intention to eat healthy food at restaurants.

H4. Cognitive attitude toward eating healthful food (low-calories) has a positive effect on the intention to eat healthy food at restaurants.

\subsubsection{Subjective norm classification}

A subjective norm was the determined opinions of others who were close and essential to a person and who maintain influence over decision-making that influences a person's behavior to execute or not execute an action. The beliefs that compose subjective norm were normative. These beliefs were social stress from essential referent individuals or groups who confirmed or refused a person's behavior, and the motives to reply to these pressures (Ajzen, 1991; Tommasetti et al., 2018). Bagozzi et al. (2000) found that subjective norms influenced consumption at fast-food restaurants. Previous studies showed that in the area of nutritional labeling, limited proof proposed that referent groups affected reading nutritional labels. The more social stress people feel, the more probable they were to intent to consume healthful foods (Kim et al., 2003; Rah et al., 2004).

Whilst social norms were traditionally conceptualized as both injunctive and descriptive norms (Rimal and Real, 2005; Rivis and Sheeran, 2003), the notion of social norms in the TPB was exemplified only by injunctive norms. Injunctive norms referred to a person's perception of "what significant others think the person ought to do," whereas descriptive norms referred to a person's perception of "what significant others themselves do" (Rivis and Sheeran, 2003, p. 219). Tuu et al. (2008) found 
favorable influences of both injunctive and descriptive norms on the intention to consume fish. Injunctive norms had been examined in the shape of subjective norms within the TPB and had been confirmed to be a significantly favorable predictor of intentions to consume healthy foods or avoid unhealthy foods (Kassem et al., 2003; Kim et al., 2003; Sjoberget al., 2004).

Moreover, Ball et al. (2010) reported that people who thought that many people around them often ate fast food or drank soft drinks were more probable to eat and drink those items. Lally et al. (2011) had the same findings asserting the prospective role of descriptive norms in evolving efficient interventions to promote healthful eating. Therefore, the researcher suggested the fifth and sixth hypotheses as follows:

H5. Injunctive norms regarding eating healthful food (low-calories) have a positive effect on the intention to eat healthy food at restaurants.

H6. Descriptive norms regarding eating healthful food (low-calories) have a positive effect on the intention to eat healthy food at restaurants.

\subsubsection{Perceived behavioral control}

The third determinant for the behavioral intention was perceived behavioral control. It was defined as "the perceived ease or difficulty of executing the behavior" (Ajzen, 1991, p.188). The acceptable notion was that the whole set of attainable control beliefs determined perceived behavioral control. These beliefs meant a person's perception of the existence of resources and opportunities required to perform a specific behavior, and evaluation of the level of significance of such resources and chances for the achievement of outcomes (Hasbullah et al., 2014). Control factors had additional classification internal control factors connected to awareness /selfefficiency, and external control factors connected to the environment (Ajzen, 1991). Regarding healthful behavior pertain to food, many researchers investigated the relationship between perceived behavioral control and intention to execute a behavior (Dean et al., 2008; Pawlak and Malinauskas, 2008; Pawlak et al., 2009). The restaurant sector had used perceived behavioral control to foresee consumers' terms of dissatisfaction, showing a favorable influence on behavioral intention (Cheng et al., 2005). Although previous studies found that perceived behavioral control affected the formulation of behavioral intention, limited investigation considered a correlation between perceived behavioral control and choosing healthy food. Therefore, current research supposed seventh hypothesis as follows:

H7. Perceived behavioral control overeating healthful food (low-calories) has a positive effect on the intention to eat healthy food at restaurants.

\subsubsection{Behavioral intention}

Intention was defined as a plan to act a specific behavior, it was an accepted, probably the most important factor, for directly foreseeing behavior (Ajzen, 1991; LaMorte 2019). The assumption was that formulation of behavioral intention was an immediate preceding of behavior and divided into three types of cognitions: attitude, subjective norm, and perceived behavioral control, which influenced by them (Ajzen, 2002). Therefore, current study uses behavioral intention as an outcome. Thus, the current research assumed the eighth hypothesis. 
H8. The behavioral intention has a positive effect on eating healthful food at restaurants.

\subsection{Restaurant customers' behavior toward healthy food}

Unilever's Food Solutions Division (2012) indicated that consumers globally from 10 countries were calling for the provision of more information about food when eating out. Two-thirds of people sought the healthful items on a menu, even if they did not choose them. Three-quarters of the respondents were incapable to identify the recommended daily allowance of fat. Additionally, $45 \%$ considered the healthful dishes were smaller in size, 57\% thought them to be more expensive and $43 \%$ realized them as less appealing. Almost two-thirds of those questioned would like a 'slightly' healthful dish when dining out.

Furthermore, the fast-food chain, customer age, gender, calorie use and calorie awareness were independently correlated with total calories consumed. When three purchasing manners were added to the model, calorie use, but not calorie awareness, remained correlated with total calories consumed. The three purchase manners collectively formed the majority of variance in calorie totals (Brissette et al., 2013). Additionally, age, education level, profession and marital status, distance to the nearest fast-food restaurant from their home had statistically significant and they were the vital dimensions in the purchasing of fast food in Sri Lanka (Aruppillai and Phillip, 2015). Some market segments would eat out more often in restaurants if Nutritional Information (NI) was available. Segments interested in NI were females, those aged 35 to 65 , and those belonging to the higher income and college-educated strata. NI that consumers were most concerned about was fat, saturated fat, and transfat (Josiam and Foster, 2009). Therefore, the current research suggested the ninth hypothesis.

H9: There are statistically significant differences between respondents' demographic characteristics (gender, age, income, marital status, and education levels) of eating healthy food in restaurants.

Health status and health attitude for seniors were positively associated with healthrelated family restaurant selection criteria. Senior customers who had a positive healthful attitude were ready to spend more money on their healthful items menu (Lee and McCleary, 2012). Gallicano et al. (2012) found that customers responded to nutritional labels and used them in their choice in full-service restaurants. Those customers who selected the healthful menu item were significantly more concerned about a healthful lifestyle.

Furthermore, ten individual factors (health, body image, weight control, feeling better, unappealing food, cost perception, shortage of knowledge, stress, and shortage of self-control and negative effects) affected customers' healthful eating behaviors at restaurants. Five environmental factors (healthful indications, social influence, availability of healthful menu, price policy and unhealthful indications) also affected their healthy eating behaviors (Jeong et al., 2019). 


\subsection{Research framework}

Based on a thorough literature review, an integrated conceptual model has been conducted to measure the customers' behavior towards eating healthy food in restaurants and the variables affecting this behavior. The current model depended on the Theory of Planned Behavior. It adapted from Kim et al., (2013) who displayed behavioral intentions' relationships to the predictors (attitude, subjective norm, and perceived behavioral control), and the association of these former dimensions with variables of beliefs (behavioral, normative, and control beliefs). Jun et al., (2014) assessed the hierarchical relationships amongst values, attitudes, and behavior toward eating healthy food relied on the value-attitude-behavior model. They investigated the influences of realized health value on attitudes toward low-calorie foods, specifically realized taste and healthfulness, and behavioral intentions regarding these foods. Kang et al., (2015) examined the relationships between health value and "interest in healthy food", "hedonic expectations", and "positive outcome expectations" variables. They also examined the influences of the last three variables on food choice intentions. Jun and Arendt (2016) measured the influences of affective and cognitive attitudes, Injunctive and descriptive norms, perceived behavioral control, regarding eating healthful food at restaurants had a favorable influence on intention and willingness to eat healthy food. They also investigated the prototype image negative influence of the typical individual who ate unhealthy foods on willingness to eat healthy food. They assessed the influence of behavioral intention, behavioral willingness, and perceived behavioral control on eating healthy food. Jeong and Ham (2018) evaluated the relationships between health belief factors as perceived threats, perceived benefits, perceived barriers, and cues to action, and customers' use of menu labels.

The current research adopted the theory of planned behavior applied by Kim et al., (2013), and the extended theory of planned behavior applied by Jun and Arendt (2016). Thus, the current conceptual model concentrates on assessing the influences of main constructs on customers' healthy eating behavior at restaurants that elicited from previous studies. These constructs are perceived health problems of eating highcalorie food, positive outcomes of eating healthful food (low-calorie food), affective and cognitive attitudes, injunctive and descriptive norms, and perceived behavioral control toward eating healthful food, which have influences on customers' behavioral intention. The behavioral intention influences customers' behavior of eating healthful food (low-calorie food). The researcher added two new variables as "perceived health problems of eating high-calorie food", "positive outcomes of eating healthful food (low-calorie food)" that influence customers' behavioral intentions and behaviors of eating healthful food at restaurants. 


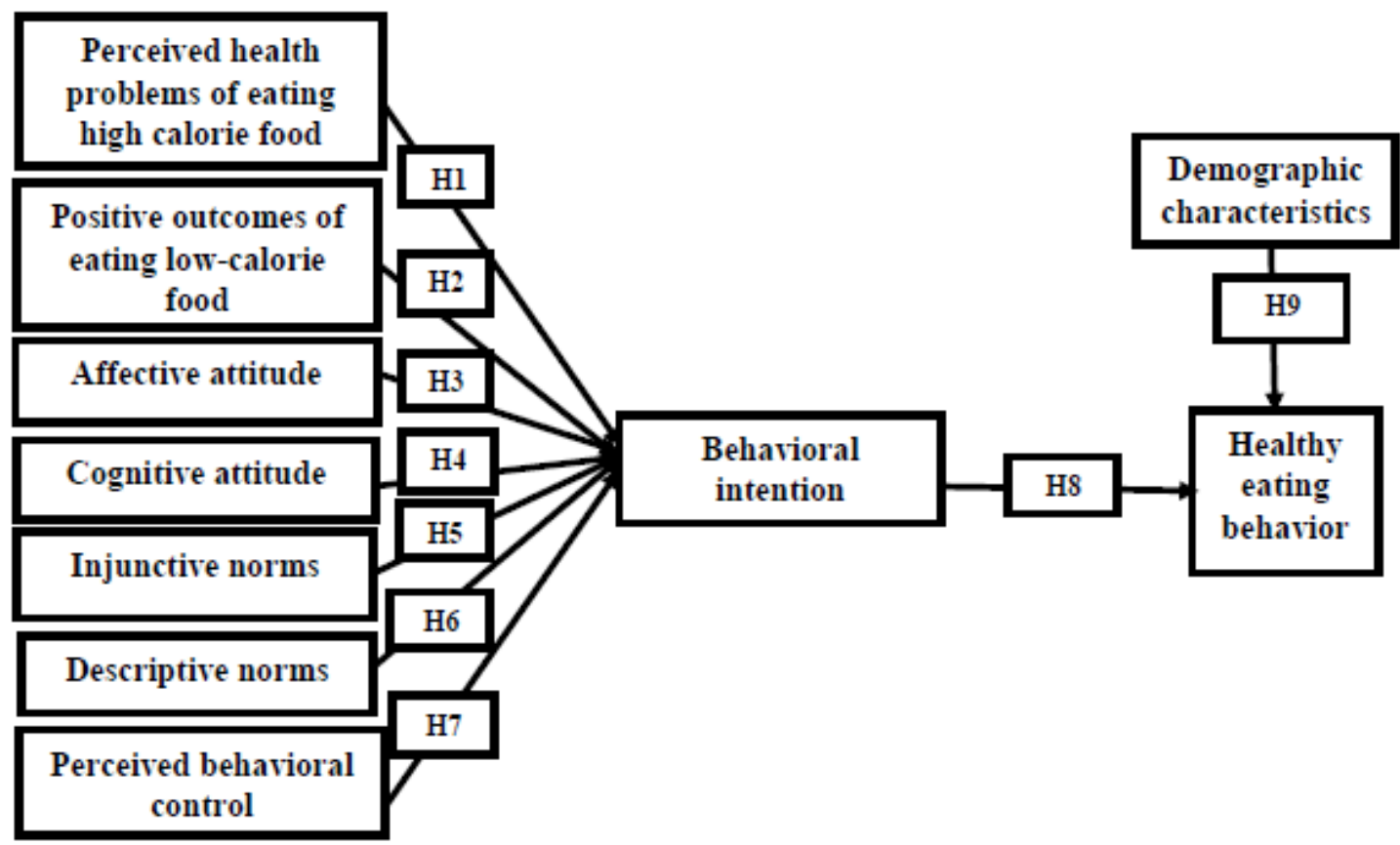

Fig.1. Proposed model: Factors affecting on restaurant customers' behavior toward eating healthy food

Source: Kim et al., (2013), Jun et al., (2014), Kang et al., (2015), Jun and Arendt (2016), Jeong and Ham (2018)

\section{Methodology}

\subsection{Research Population and Sampling}

The inhabitants of Minia district were the population of the research that represented 940421 people of Minia Governorate population (Central Agency for Public Mobilization and Statistics of Egypt, 2017). The researcher determined the sample size from an infinite population by the following formula. Taherdoost (2017) stated that " $\mathrm{n}$ " was the required sample size. "P" was the percentage occurrence of a state or condition. The percentage occurrence of how a specific question, will be answered is $\mathrm{P}(100-\mathrm{P}) . \mathrm{P}=$ the percentage of a sample having a characteristic. Bartlett et al. (2001) suggested that researchers should use $50 \%$ as an estimate of $\mathrm{P}$, as this led to the maximization of variance and produce the maximum sample size. Taherdoost (2017) also added that "E" was the percentage maximum error required, where a $5 \%$ margin of error was acceptable in social research. "Z" was the value corresponding to the level of confidence required. In management research the typical levels of confidence used are 95 percent (0.05: a $\mathrm{Z}$ value equal to 1.96$)$.

$$
\mathrm{n}=\frac{\mathrm{p}(100-\mathrm{p}) \mathrm{z}^{2}}{\mathrm{E}^{2}} \mathrm{n}=\frac{50^{\times}(100-50) \times(1.96)^{2}}{(5)^{2}} \mathrm{n}=\frac{2500 \times 3.8416}{25} \quad \mathrm{n}=\frac{9604}{25}=385
$$

Thus, the target sample was 385 customers of the research population who visit the chain and independent restaurants located in down town and Cornish el Nile of Minia district. They were 52 different restaurants which consisted of eight fine dining, 16 
casual dining, 20 fast-food restaurants and eight hotel restaurants (Tourism office in Minia Governorate, 2020). A simple random sampling technique was adopted in the research.

\subsection{Survey instrument}

To achieve the research aim, a quantitative approach was adopted based on a questionnaire. A structured questionnaire was developed and directed to the restaurants customers. Many studies clarified these variables that the researcher relied on to design the questionnaire dimensions as Kim et al., (2013), Jun et al., (2014), Kang et al., (2015), Jun and Arendt (2016), Jeong and Ham (2018), Jeong et al., (2019). The researcher adopted the theory of planned behavior that applied by Kim et al., (2013), and the extended theory of planned behavior that applied by Jun and Arendt (2016). The questionnaire included 54 questions. The first section involved demographic variables, which were collected with closed-ended questions through five factors like gender, age, education, income, and marital status. The second section included 12 questions. The second and third question asked the respondents' height and weight to account for the BMI. The fourth question asked them to type of restaurants they prefer to visit. The fifth question related to the monthly expenditure rate on eating meals in restaurants. Defining healthy food was involved in the sixth question. They were asked which restaurants offered healthy food to them in the seventh and eighth questions. Posting restaurants to menu calorie labels and their effect on customer purchasing decision of healthy food were asked in the ninth and tenth questions. The frequencies of selecting healthy food in restaurants and the barriers of not choosing it were asked in the eleventh and twelfth questions. The respondents were asked why healthy food attract them in the thirteenth question.

Furthermore, the questionnaire comprised of nine dimensions which were measured according to the five-point Likert scale: $1=$ strongly disagree, $2=$ disagree, $3=$ neutral, $4=$ agree and 5=strongly agree. The third section entitled the perceived health problems of consuming high-calorie food, which included seven variables. These variable were: If I choose high-calorie food, (1) my physical health will get a health problem like heart diseases, (2) my chances of having a health problem are high like obesity, (3) I feel that my chances of having a health problem in the future are high like diabetes, (4) there is a possibility that I will get a health problem like high blood pressure, (5) health problems would negatively affect my life like increasing blood cholesterol levels, (6) health problems would be serious for me, and (7) health problems would disrupt my life. The fourth section represented the positive outcomes of eating healthy (low-calorie) food, which involved seven variables. They were (1) I believe that eating low-calorie food helps to lose weight, (2) I believe that consuming low-calorie food keeps my body in shape, (3) I believe that eating low-calorie food keeps my cholesterol level under control, (4) The consumption of low-calorie food improves my health, (5) I think that low-calorie foods at restaurants are healthier than regular food choices, (6) The healthfulness of low-calorie food at restaurants makes a difference to me, and (7) It is important for me that my daily diet contains low-calorie restaurant foods. Additionally, the fifth section was titled: customers' affective attitude toward healthy eating behavior, which comprised three variables. They were 
(1) when I choose low-calorie food at restaurant, I would be extremely unpleasant to extremely pleasant. (2) When I choose low-calorie food at restaurant, I would be extremely unenjoyable to extremely enjoyable. (3) When I choose low-calorie food at restaurant, I would be extremely boring to extremely interesting. Furthermore, the sixth sections represented cognitive customers' attitude toward healthy eating behavior, which encompassed three variables. These variables were (1) Eating healthful food at restaurants would be extremely bad to excellent. (2) Eating healthful food at restaurants would be extremely harmful to extremely beneficial. (3) Eating healthful food at restaurants would be extremely foolish to extremely wise.

The seventh section assessed customers' injunctive norms toward healthy eating behavior that involved three variables. These variables were (1) people who are important to me are likely to think I should choose low-calorie food. (2) People who are important to me would approve of my choosing low-calorie food. (3) People who are important to me want me to choose low-calorie food. Moreover, the eighth section were customers' descriptive norms regarding healthy eating behavior, which included three variables. These variables were (1) a number of people I know think of choosing low-calorie food when they eat out. (2) A number of people I know try to choose lowcalorie food when they eat out. (3) A number of people I know have chosen lowcalorie food when they eat out. Perceived behavior control concerning eating healthy food was the ninth section that involved three variables. These variables were (1) I feel in complete control of whether I choose low-calorie food at restaurants. (2) If I wanted to, I could easily choose healthful food with low-calories at restaurants. (3) At restaurants, I have control over choosing healthful food with low calories. The tenth section was customers' behavioral intention toward eating healthy food, which comprised five variables. These variables were (1) I plan to eat low-calorie food at restaurants. (2) I intend to eat low-calorie food at restaurants. (3) I will try to eat low calorie menu items at restaurants. (4) I will recommend low-calorie foods at restaurants to my friends or others. (5) I will say positive things about low-calorie foods at restaurants to other. The eleventh section encompassed three variables respectively and assessed self-reported behavior toward eating healthy food. These variables were (1) when I eat out, if healthful food are available, I choose low-calorie food. (2) When I eat out, if healthful food are available, I often times choose low calorie food. (3) When I eat out, even if healthful food are available, I often times choose high-calorie food.

\subsection{Data collection procedures}

Collecting data was depended on printed or online questionnaires. They were distributed to the customers who visited different restaurants. The respondent filled the questionnaire after finishing the meal and return it to the researcher, or received the Google Drive link of the questionnaire and asked to fill and submit it at a later time. A total of 500 questionnaires were distributed to them, whereas 425 questionnaires were collected. The non-valid questionnaires were 40 forms, whereas 385 questionnaires were valid to analyze. 


\subsection{Data Analysis}

Data analysis was conducted using SPSS version 22. Appropriate statistical analyses were performed such as frequencies, percentages, means, standard deviation, and Cronbach's alpha. Pearson correlation, simple linear regression, and ANOVA test were applied.

\subsection{Data validity and reliability}

\subsubsection{Data validity}

To validate the questionnaire for collecting data concerning its reliability, format, and ability to measure the research constructs, it was distributed to some restaurants' customers in Minia district. Moreover, Academic professors revised the questionnaire, showed interest, and interacted with the researcher regarding the questionnaire which adds to its validity. The questionnaire was then updated and refined to reflect the comments and suggestions received from them.

\subsubsection{Data reliability}

The researcher applied the reliability test, before proceeding with further analysis. The reliability of the questionnaire indicated stability and internal consistency of its questions. Cronbach's Alpha was used to measure a scale's reliability, in which its index ranged from 0.0 to 1.0. The researchers should target a value closer to 1.0 , as the Alpha value proves that the research instrument is consistent. In the social sciences, the threshold value of 0.7 is acceptable.

\section{Table 1}

Cronbach's Alpha

\begin{tabular}{|l|c|c|}
\hline Variables & Cronbach's Alpha & No. of Items \\
\hline $\begin{array}{l}\text { Perceived health problems of eating high } \\
\text { calories food }\end{array}$ & 0.93 & 7 \\
\hline $\begin{array}{l}\text { Positive outcomes of eating healthful (low } \\
\text { calorie) food }\end{array}$ & 0.93 & 7 \\
\hline Affective attitude & 0.87 & 3 \\
\hline Cognitive attitude & 0.77 & 3 \\
\hline Injunctive norm & 0.90 & 3 \\
\hline Descriptive norm & 0.88 & 3 \\
\hline Perceived behavior Control & 0.83 & 3 \\
\hline Behavioral intention & 0.91 & 5 \\
\hline Self-reported behavior & 0.71 & 3 \\
\hline Total scale variables & 0.94 & 37 \\
\hline
\end{tabular}

Table one shows that Cronbach's alpha value of questionnaire dimensions ranged from 0.71 to 0.93 and for total questionnaire items was 0.94. It indicated an acceptable Cronbach's Alpha value for each variable, whenever Cronbach's Alpha was acceptable if it was more than 0.70 (Nunnally, 1978). 


\section{Results and Discussion}

Table 2

Demographic Characteristics of the Respondents

\begin{tabular}{|l|l|c|c|}
\hline Variables & Freq. & $\%$ \\
\hline Gender & Male & 227 & 59 \\
\cline { 2 - 4 } & Female & 158 & 41 \\
\hline Total & & 385 & 100 \\
\hline Age & Less than 18 years & 8 & 2 \\
\hline & 18 to less than 25 years & 139 & 36.1 \\
\hline & 25 to less than 35 years & 121 & 31.4 \\
\hline & 35 to less than 45 years & 63 & 16.4 \\
\hline & 45 to less than 55 years & 31 & 8.1 \\
\hline & 55 years and older & 23 & 6 \\
\hline Total & & 385 & 100 \\
\hline Education & Primary education & 17 & 4.4 \\
\hline & Secondary education & 49 & 12.7 \\
\hline & Bachelor & 211 & 54.8 \\
\hline & Diploma & 28 & 7.3 \\
\hline & Master degree & 31 & 8.1 \\
\hline & Doctorate degree & 49 & 12.7 \\
\hline Total & & 385 & 100 \\
\hline Household income L.E. (Monthly) & Less than 5000 & 215 & 55.8 \\
\hline & 5000 to less than 10000 & 124 & 32.2 \\
\hline & 10000 to less than 20000 & 31 & 8.1 \\
\hline & 20000 to less than 30000 & 9 & 2.3 \\
\hline & 30000 to less than 40000 & 1 & 0.3 \\
\hline & 40000 and over & 5 & 1.3 \\
\hline Total & & 385 & 100 \\
\hline Marital status & Single & 201 & 52.2 \\
\hline & Married & 163 & 42.3 \\
\hline & Divorced & 8 & 2.1 \\
\hline & Widower & 13 & 3.4 \\
\hline Total & & 385 & 100 \\
\hline & & & 9 \\
\hline
\end{tabular}

Table 2 displays that males and females represented $59 \%$ and $41 \%$ of the respondents respectively. Regarding the respondents' age, $83.9 \%$ of them ranged from 18- 45 years, which represented youth ages. Only $14.1 \%$ of them ranged from 45 to older than 55 years. Children represented $2 \%$ of them. Concerning respondents' education levels, more than half $(54.8 \%)$ of them got a bachelor degree, while $28.1 \%$ of them got a diploma, master, and doctorate degree. However, only $17.1 \%$ of them got primary and secondary education. It referred that $82.9 \%$ of the respondents were highly educated (bachelor and post-graduate degrees). 
Moreover, $55.8 \%$ of the respondents' household income was less than 5000 L.E., while the household income of $32.2 \%$ of them ranged from 5000 L.E. to less than 10000. These two categories represented $88 \%$ of the customers' income in Minia district. Therefore, it might reflect on their expenditure when eating out. They might purchase high-calorie meals at low prices such as fast food. Only $12 \%$ of the respondents' income ranged from 10000 L.E. to more than 40000. Regarding the respondents' marital status, $52.2 \%$ of them were single, and $42.3 \%$ of them were married. These two categories represented $94.5 \%$ of the respondents, while only $5.5 \%$ of the respondents were divorced and widower.

Table 3

Information of restaurants' customers in Minia District

\begin{tabular}{|c|c|c|c|}
\hline \multicolumn{2}{|c|}{$\begin{array}{ll}\text { Variables } \\
\end{array}$} & Freq. & $\%$ \\
\hline \multirow{6}{*}{$\begin{array}{l}\text { Customers' } \quad \text { Height } \\
(\mathrm{cm}) \\
\text { Mean height }=3.1 \\
\text { Std. Deviation }=0.95\end{array}$} & Less than 150 & 9 & 2.3 \\
\hline & 150 to less than 160 & 101 & 26.2 \\
\hline & 160 to less than 170 & 149 & 38.7 \\
\hline & 170 to less than 180 & 99 & 25.7 \\
\hline & 180 to less than 190 & 26 & 6.8 \\
\hline & 190 to less than 200 & 1 & 0.3 \\
\hline Total & & 385 & 100 \\
\hline \multirow{6}{*}{$\begin{array}{l}\text { Customers' Weight }(\mathrm{kg}) \\
\text { Mean weight }=2.26 \\
\text { Std. Deviation }=0.85 \\
\end{array}$} & less than 60 & 61 & 15.8 \\
\hline & 60 to less than 80 & 198 & 51.8 \\
\hline & 80 to less than 100 & 97 & 25.2 \\
\hline & 100 to less than 120 & 24 & 6.2 \\
\hline & 120 to less than 140 & 4 & 1 \\
\hline & 140 and over & 1 & 0.3 \\
\hline Total & & 385 & 100 \\
\hline \multirow{5}{*}{\begin{tabular}{|l}
$\begin{array}{l}\text { Customers' favorite } \\
\text { restaurant }\end{array}$ \\
\end{tabular}} & Hotel restaurant & 23 & 6 \\
\hline & Casual dining & 94 & 24.4 \\
\hline & Fine dining & 47 & 12.2 \\
\hline & Fast food & 90 & 23.4 \\
\hline & All above & 131 & 34 \\
\hline Total & & 385 & 100 \\
\hline \multirow{6}{*}{$\begin{array}{l}\text { Monthly expenditure } \\
\text { on eating at at } \\
\text { restaurants }\end{array}$} & Less than $10 \%$ & 127 & 33 \\
\hline & $10-20 \%$ & 116 & 30.1 \\
\hline & $21-30 \%$ & 71 & 18.4 \\
\hline & $31-40 \%$ & 39 & 10.1 \\
\hline & $41-50 \%$ & 22 & 5.7 \\
\hline & More than $50 \%$ & 10 & 2.6 \\
\hline Total & & 385 & 100 \\
\hline & & \multicolumn{2}{|c|}{ Continued } \\
\hline
\end{tabular}




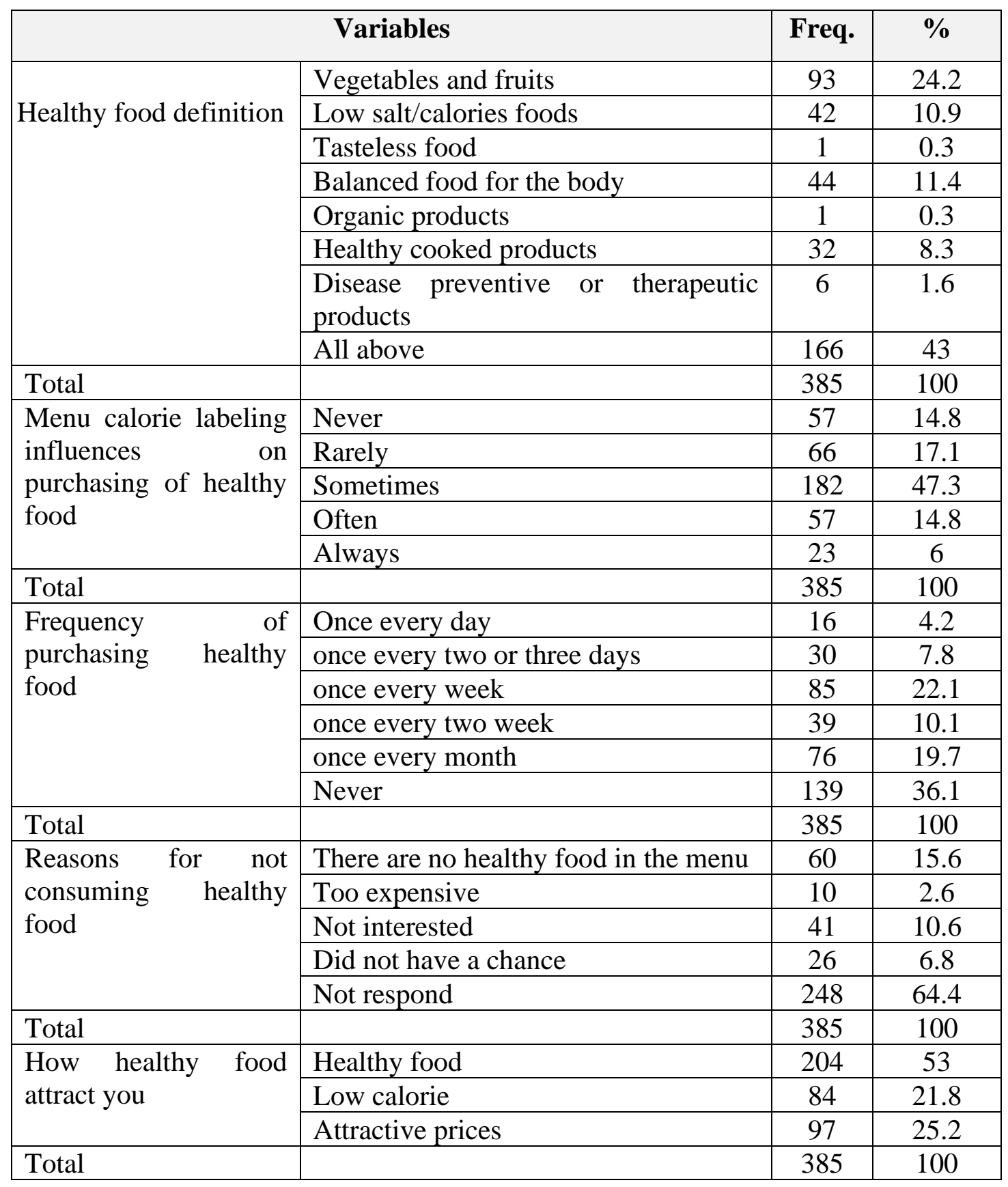

The results in table 3 indicate that mean of the respondents' height ranged from 160$170 \mathrm{~cm}$, while their weight means ranged from $60-80 \mathrm{Kg}$. According to the averages of these values, the BMI of the respondents $=70 \mathrm{~kg} /(1.65 \mathrm{~m})^{2}=25.7$. It indicated that they suffered from overweight. Thus, they might suffer from cardiovascular diseases and deaths in the short and long term due to high BMI. It agreed with Massachusetts Medical Society (2017) which stated that high BMI interpreted 4.0 million deaths globally due to cardiovascular disease. 
Regarding the respondents' favorite restaurants, $34 \%$ of them preferred all types of restaurants. There were $47.8 \%$ of them preferred casual dining and fast-food restaurants, while $18.2 \%$ of the respondents preferred fine dining and hotel restaurants. This agreed with Saksena et al. (2018) who indicated that Americans' proportion of energy intake from restaurants increased from $17 \%$ in 1977-78 to $34 \%$ in 2011-12. The current results disagreed with Stewart et al. (2006) who mentioned that more than half of surveyed consumers visited full-service and fast-food restaurants. It revealed that the respondents in current research intook more energy, fat and salt from eating fast food. Thus, their eating behavior was worse than the customers' behavior in the research of Stewart et al. (2006), who half of them consumed varied meals of nutritional values in full-service restaurants. The increasing rate of eating fast-food might influence the respondents' health. Moreover, the respondents' monthly expenditure rate on eating at restaurants was varied. One-third of them spent less than $10 \%$ of their income on eating at restaurants monthly and 30 $\%$ of them spent from $10-20 \%$. Only $5.7 \%$ of the respondents spent from $41-50 \%$ of their income on eating at restaurants and $2.6 \%$ of them spent more than $50 \%$. This result agreed with the respondents' low income that mentioned above in table 2, but it disagreed with Stewart et al. (2006) who stated that spending on foods from restaurants had also grown to account for about half of total food expenditures in 2004, up from $34 \%$ in 1974. It referred to when household income increased, spending on eating at restaurants might also increase.

Furthermore, there was a shortage in the perceived awareness of the healthful food definition among $57 \%$ of the respondents, who selected one part of the definition. There were $43 \%$ of them who selected "all above" choice, perceived the integrated definition of healthful food as mentioned by Onyango and Wasike (2018) it should involve conventional, medical, healthful cooked food, vegetarian, gluten-free and seafood products. In addition, only $20.8 \%$ of the respondents often or always used menu calorie labeling to select healthful food, while $79.2 \%$ of them never, rarely, or sometimes used it to select healthful food from the menu. It indicated low perceived awareness among the respondents who visit restaurants for using menu calorie labeling and its importance. Therefore, $79.2 \%$ of the respondents might intake more saturated fat, calories, sodium more than their recommended daily allowance due to frequent eating out and not using menu labeling. It agreed with Unilever's Food Solutions Division (2012). This result agreed with Story et al. (2008) who revealed that most consumers might be unaware of the high levels of calories, fat, saturated fat, and sodium found in many menu items, and might underestimate actual calorie content by as much as $50 \%$. Furthermore, the current result disagreed with Brissette et al. (2013) who found that calorie use, and calorie awareness were independently correlated with total calories consumed.

Moreover, the results show that only $12 \%$ of the respondents had healthful eating behavior, whereas they selected healthful food at restaurants daily or every two or three days. There were $36.1 \%$ who never chose healthful food. Also, the respondents who slightly selected healthful foods at restaurants represented $51.9 \%$. They chose healthy food once every week; once every two week; once every month. These results 
disagreed with Lee and McCleary (2012) who showed that senior customers who had a positive healthful attitude were ready to spend more money on their healthful items menu. It also disagreed with Gallicano et al. (2012) who found that customers who had a healthful lifestyle responded to nutritional labels and used them in full-service restaurants.

Regarding the reasons for not selecting healthy food, $15.6 \%$ of the respondents mentioned that restaurants did not offer healthy food; $10.6 \%$ of them were not interested in healthy food; $2.6 \%$ of them claimed that healthy foods were too expensive. It might be due to customers and restaurants' managers did not have awareness of the importance of healthy foods on public health. These results disagreed with Lee and McCleary (2012); Gallicano et al. (2012). On the other hand, healthful foods attracted $53 \%$ of the respondents due to their nutritional value; 21.8 $\%$ of them selected healthy foods due to containing low calories. There were also 25.2 $\%$ of them chose healthful food due to attractive prices. It illustrated that there was a segment of the customers, who had health consciousness needed to eat healthful food when visiting restaurants.

\section{Table 4}

Information about healthy foods in restaurants

\begin{tabular}{|l|l|l|l|}
\hline Variables & Freq. & $\%$ \\
\hline Restaurants offer healthy meals & Yes & 151 & 39.2 \\
\cline { 2 - 4 } & No & 234 & 60.8 \\
\hline Total & & 385 & 100 \\
\hline $\begin{array}{l}\text { Types of restaurants that provide healthy } \\
\text { foods }\end{array}$ & Hotel restaurant & 121 & 31.4 \\
\hline & Casual dining & 92 & 23.9 \\
\hline & Fine dining & 128 & 33.2 \\
\hline Total & Fast food & 44 & 11.4 \\
\hline Restaurants post menu calorie labeling & & 385 & 100 \\
\hline Total & Yes & 78 & 20.3 \\
\cline { 2 - 4 } & No & 307 & 79.7 \\
\hline
\end{tabular}

In table 4 , the results display that $60.8 \%$ of the respondents mentioned that restaurants did not provide healthful food, while $39.2 \%$ of them reported the opposite. It referred that there was a shortage of menu planning for these restaurants to involve healthful food. It agreed with Story et al. (2008) mentioned that frequent eating out was related to higher caloric intake, weight gain, and obesity.

However, $33.2 \% ; 31.4 \%$ of the respondents reported that fine dining; hotel restaurants provided healthful food respectively, while $23.9 \% ; 11.4 \%$ of them stated that casual dining; fast-food restaurants offered healthful food respectively. It revealed that fine dining and hotel restaurants interested in providing healthful food more than casual dining and fast-food restaurants. It agreed with Hollands et al. (2014) who indicated that fast-food density had a positive association with customers' BMI whereas full-service and non-chain restaurant density had a negative association. 
Moreover, $79.7 \%$ of people surveyed mentioned that the restaurants did not post menu calorie labeling on the menu, while only $20.3 \%$ of them reported the opposite. It clarified that most restaurants had not aware of the menu calorie labeling importance for customers' health and the restaurant's image. The current results agreed with Unilever's Food Solutions Division (2011) which found that almost 90\% of people surveyed desired for nutritional information to be available when eating out. However, the current results disagreed with Josiam and Foster (2009) who indicated that some market segments would eat out more often in restaurants if Nutritional Information (NI) was available.

\section{Table 5}

Mean rating and standard deviation of the constructs

\begin{tabular}{|l|l|l|l|l|l|}
\hline Variables & Min. & Max. & Mean & St. D & Evaluation \\
\hline $\begin{array}{l}\text { Perceived health problems of } \\
\text { consuming high-calorie food }\end{array}$ & 7 & 35 & 25.07 & 6.60 & High \\
\hline $\begin{array}{l}\text { Positive outcomes of eating healthy } \\
\text { food }\end{array}$ & 7 & 35 & 25.31 & 6.07 & High \\
\hline Affective attitude & 3 & 15 & 9.98 & 2.32 & Moderate \\
\hline Cognitive attitude & 4 & 15 & 10.73 & 2.04 & High \\
\hline Injunctive norm & 3 & 15 & 10.02 & 2.59 & Moderate \\
\hline Descriptive norm & 3 & 15 & 9.05 & 2.53 & Moderate \\
\hline Perceived behavior Control & 3 & 15 & 9.08 & 2.46 & Moderate \\
\hline Behavioral intention & 5 & 25 & 15.79 & 4.05 & Moderate \\
\hline Self-reported behavior & 3 & 15 & 8.91 & 2.14 & Moderate \\
\hline
\end{tabular}

According to table 5, averages of the variables ranged from 8.91-25.31. The highest value of them was for "positive outcomes of eating healthy food", while the lowest value was for "self-reported behavior". The average of these variables ranged from moderate to high. It revealed there was a leakage of customers' affective attitude; subjective norms; behavioral control; intentions; behavior towards eating healthful food. It might lead to obesity; heart; diabetes diseases in customers in the long term. 
Table 6

Correlation Matrix of the constructs

\begin{tabular}{|c|c|c|c|c|c|c|c|c|c|}
\hline & $\begin{array}{l}\text { Perceived } \\
\text { health } \\
\text { problems }\end{array}$ & $\begin{array}{l}\text { Positive } \\
\text { outcomes }\end{array}$ & $\begin{array}{l}\text { Affective } \\
\text { attitude }\end{array}$ & $\begin{array}{l}\text { Cognitive } \\
\text { attitude }\end{array}$ & $\begin{array}{l}\text { Injunctive } \\
\text { norm }\end{array}$ & $\begin{array}{l}\text { Descriptive } \\
\text { norm }\end{array}$ & $\begin{array}{l}\text { Perceived } \\
\text { behavior } \\
\text { Control }\end{array}$ & intention & Behavior \\
\hline Positive outcomes & $0.678 * *$ & & & & & & & & \\
\hline Affective attitude & $0.145 * *$ & $0.215 * *$ & & & & & & & \\
\hline Cognitive attitude & $0.380 * *$ & $0.429 * *$ & $0.515 * *$ & & & & & & \\
\hline Injunctive norms & $0.402 * *$ & $0.495 * *$ & $0.409 * *$ & $0.485 * *$ & & & & & \\
\hline Descriptive norms & $0.188 * *$ & $0.269 * *$ & $0.325 * *$ & $0.201 * *$ & $0.403 * *$ & & & & \\
\hline $\begin{array}{l}\text { Perceived behavior } \\
\text { Control }\end{array}$ & $0.167 * *$ & $0.199 * *$ & $0.293 * *$ & $0.287 * *$ & $0.403 * *$ & $0.404 * *$ & & & \\
\hline intention & $0.363 * *$ & $0.376 * *$ & $0.402 * *$ & $0.412 * *$ & $0.521 * *$ & $0.473 * *$ & $0.581 * *$ & & \\
\hline Behavior & $0.267 * *$ & $0.284 * *$ & $0.299 * *$ & $0.361 * *$ & $0.397 * *$ & $0.332 * *$ & $0.535 * *$ & $0.615 * *$ & \\
\hline Total & $0.751 * *$ & $0.784 * *$ & $0.499 * *$ & $0.630 * *$ & $0.721 * *$ & $0.533 * *$ & $0.549 * *$ & $0.750 * *$ & $0.603 * *$ \\
\hline
\end{tabular}

**. Correlation is significant at the 0.01 level

A seen in table 6, there was a significant statistical correlation between the constructs; between each variable and the total grade of all variables at the 0.01 significance level. These results showed that the relationship among variables ranged from low to moderate, while between each variable with a total grade of variables was moderate. 
Table 7

Linear regression of the constructs affecting on customers' behavioral intentions toward eating healthful food

\begin{tabular}{|c|c|c|c|c|c|c|c|c|c|c|}
\hline Independent variables & $\begin{array}{l}\text { Dependent } \\
\text { variable }\end{array}$ & Constant & Beta & $\mathrm{T}$ & Sig. & $\mathrm{F}$ & Sig. & $\mathrm{R}$ & $\mathrm{R}^{2}$ & $\begin{array}{c}\text { Adjusted } \\
\mathrm{R}^{2}\end{array}$ \\
\hline Perceived health problems & \multirow{7}{*}{$\begin{array}{l}\text { Behavioral } \\
\text { intentions }\end{array}$} & 10.21 & 0.36 & 7.6 & 0.01 & 57.9 & 0.01 & 0.36 & 0.13 & 0.13 \\
\hline Positive outcomes & & 9.5 & 0.38 & 7.9 & 0.01 & 62.7 & 0.01 & 0.38 & 0.14 & 0.14 \\
\hline Affective attitude & & 8.8 & 0.40 & 8.6 & 0.01 & 73.7 & 0.01 & 0.40 & 0.16 & 0.16 \\
\hline Cognitive attitude & & 7.01 & 0.41 & 8.8 & 0.01 & 77.9 & 0.01 & 0.41 & 0.17 & 0.17 \\
\hline Injunctive norm & & 7.6 & 0.52 & 11.9 & 0.01 & 142.6 & 0.01 & 0.52 & 0.27 & 0.27 \\
\hline Descriptive norm & & 8.9 & 0.47 & 10.5 & 0.01 & 109.9 & 0.01 & 0.47 & 0.22 & 0.22 \\
\hline $\begin{array}{l}\text { Perceived behavior } \\
\text { Control }\end{array}$ & & 7.1 & 0.58 & 13.9 & 0.01 & 193.8 & 0.01 & 0.58 & 0.33 & 0.33 \\
\hline
\end{tabular}

Table 7 displays that the perceived "health problems of eating high-calorie foods" and "positive outcomes of eating healthy food" had influences on predicting of customers' behavioral intentions towards eating healthful food by $13 \%$; $14 \%$ respectively. It indicated these two factors slightly influenced restaurant customers' behavior towards eating healthful food. The regression equation for the first variable was "customers' behavioral intentions $=10.21+0.22 \times$ perceived health problems of eating highcalorie foods". The regression equation for the second variable was "customers' behavioral intentions $=9.5+0.25 \times$ positive outcomes of eating healthy food. Thus, hypotheses one and two were proved positively. These results agreed with Bishop et al. (2015); Park (2011) who illustrated that as the grades of the realized health threats increased, the likelihood that conservative health behaviors were increased and the behavioral intention to require weight decrease. Moreover, it agreed with Kang et al. (2015) who found that health value was the key variable that promoted customers' intentions to consuming healthful food items. It also agreed with Sualakamala and Huffman (2010); Jeong and Ham (2018).

Moreover, "affective and cognitive attitudes" influenced predicting customers' behavioral intentions towards eating healthful food by $16 \% ; 17 \%$ respectively. The regression equation for affective attitude was "customers' behavioral intentions $=8.8+0.70 \times$ affective attitude", while the regression equation for cognitive attitude was "customers' behavioral intentions $=7.01+0.82 \times$ cognitive attitude". Therefore, hypotheses three and four were proved positively. This result disagreed with Dunn et al. (2011) who displayed that only cognitive attitudes had a significant influence on intention to eat fast-food.

245 I P a g e 
Furthermore, the cognitive attitude had a stronger influence on behavioral intentions to select healthful food than affective attitude, which disagreed with Jun and Arendt

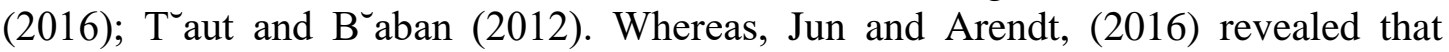
affective attitude and injunctive norms had stronger and more consistent influences on behavioral intentions and readiness to select healthful menu items than did cognitive attitude and descriptive norms.

Furthermore, "injunctive and descriptive norms" influenced predicting customers' behavioral intentions towards eating healthful food by $27 \% ; 22 \%$ respectively. The regression equation for "injunctive norms" was "customers' behavioral intentions = $7.6+0.81 \times$ injunctive norms", while the regression equation for "descriptive norms" was "customers' behavioral intentions $=8.9+0.76 \times$ descriptive norms". Therefore, hypotheses five and six were proved positively. This result disagreed with Kassem et al. (2003); Kim et al. (2003); Sjoberget al. (2004) who revealed that injunctive norms had only been confirmed to be a significantly favorable predictor of intentions to consume healthy foods or avoid unhealthy foods. The results also disagreed with Lally et al. (2011); Manning (2009); Rivis and Sheeran (2003) who illustrated the favorable role of only descriptive norms were also been proven to predict customer behavioral intentions to eat healthful food at restaurants. However, it agreed with Tuu et al. (2008) who found favorable influences of both injunctive and descriptive norms on the intention to consume fish. Furthermore, injunctive norms had stronger influence on the behavioral intentions to select healthful food than descriptive norms, which agreed with Jun and Arendt (2016). Finally, the perceived behavior control had also influence the prediction of customers' behavioral intentions towards eating healthful food by $33 \%$. The regression equation was "customers' behavioral intentions $=7.1+0.96 \times$ perceived behavior control". Therefore, hypothesis seven was proved positively. It agreed with Dean et al. (2008); Pawlak and Malinauskas (2008); Pawlak et al. (2009).

\section{Table 8}

Linear regression of restaurant customers' behavioral intentions on their behavior toward eating healthful food

\begin{tabular}{|l|l|l|l|l|l|l|l|l|l|}
\hline $\begin{array}{l}\text { Independent } \\
\text { variable }\end{array}$ & Constant & Beta & $\mathrm{T}$ & Sig. & $\mathrm{F}$ & Sig. & $\mathrm{R}$ & $\mathrm{R}^{2}$ & $\begin{array}{c}\text { Adjusted } \\
\mathrm{R}^{2}\end{array}$ \\
\hline $\begin{array}{l}\text { Behavioral } \\
\text { intentions }\end{array}$ & 3.78 & 0.62 & 15.2 & 0.01 & 231.97 & 0.01 & 0.62 & 0.38 & 0.38 \\
\hline
\end{tabular}

**Dependent variable; Behavior

The results in table 8 reveal that behavioral intentions of customers influenced predicting their behavior towards eating healthful food by $38 \%$. The regression equation was "behavior $=3.78+0.33 \times$ behavioral intentions". Thus, hypothesis eight was proved positively. It agreed with Josiam and Foster (2009). It also agreed with Gallicano et al. (2012) who found that customers, who were more concerned with a healthful lifestyle responded to nutritional labels and used them in their choice in fullservice restaurants. 


\section{Table 9}

T-Test for differences between males and females towards eating healthful food behavior

\begin{tabular}{|l|l|l|l|l|l|l|}
\hline & \multicolumn{2}{|l|}{ Males (N=227) } & \multicolumn{2}{l|}{ Females (N=158) } & T Value & Sig. \\
\cline { 2 - 5 } & Mean & St. D & Mean & St. D & $383)$ & \\
\hline Customer behavior & 8.95 & 2.42 & 8.86 & 1.67 & 0.41 & 0.68 \\
\hline
\end{tabular}

Table 9 displays that there were no differences between males and females who surveyed towards eating healthy food behavior. Whereas, T value was 0.41 at a 0.68 significance level. It indicated that they were homogenous in their behavior towards eating healthful food. The current result disagreed with Brissette et al. (2013) who indicated that the customer gender was correlated with total calories consumed in fast-food restaurants. It also disagreed with Josiam and Foster (2009) who showed that females would eat out more often in restaurants if Nutritional Information was available. They also interested in NI displayed in the restaurant menu when eating out.

\section{Table 10}

ANOVA for differences between customers' demographics towards eating healthful food behavior

\begin{tabular}{|c|c|c|c|c|c|c|}
\hline & Sum of squares & $\mathrm{df}$ & Mean square & $\mathrm{F}$ & Sig. \\
\hline \multirow[t]{3}{*}{ Age } & Between Groups & 30.01 & 5 & 6.00 & \multirow[t]{3}{*}{1.31} & \multirow[t]{3}{*}{0.26} \\
\hline & Within Groups & 1738.16 & 379 & 4.59 & & \\
\hline & Total & 1768.17 & 384 & & & \\
\hline \multirow[t]{3}{*}{ Income } & Between Groups & 5.08 & 5 & 1.02 & \multirow[t]{3}{*}{0.22} & \multirow[t]{3}{*}{0.96} \\
\hline & Within Groups & 1763.09 & 379 & 4.65 & & \\
\hline & Total & 1768.17 & 384 & & & \\
\hline \multirow{3}{*}{$\begin{array}{l}\text { Marital } \\
\text { status }\end{array}$} & Between Groups & 13.27 & 3 & 4.42 & \multirow[t]{3}{*}{0.96} & \multirow[t]{3}{*}{0.41} \\
\hline & Within Groups & 1754.90 & 381 & 4.61 & & \\
\hline & Total & 1768.17 & 384 & & & \\
\hline \multirow{3}{*}{$\begin{array}{l}\text { education } \\
\text { levels }\end{array}$} & Between Groups & 52.47 & 5 & 10.49 & \multirow[t]{3}{*}{2.32} & \multirow[t]{3}{*}{0.04} \\
\hline & Within Groups & 1715.70 & 379 & 4.53 & & \\
\hline & Total & 1768.17 & 384 & & & \\
\hline
\end{tabular}

Table 10 reveals that there were no significant differences among customers' age groups towards eating healthful food behavior. Whereas, F value was 1.31 at 0.26 significance level. It referred that all the respondents' age groups had the same behavior towards eating healthful foods, whereas they did not commit to eating healthful food behavior (see table 5). This result disagreed with Brissette et al. (2013) and Aruppillai and Phillip (2015) who found that customer age was one of the determinants that independently correlated with total calories consumed in fast food restaurants. It also disagreed with Josiam and Foster (2009) who illustrated that the customers whose ages from 35 to 65 would eat out more often in restaurants if Nutritional Information was available. They also interested in NI displayed on the menu when eating out. 
The results also show that there were no significant differences among customers' income groups towards eating healthful food behavior. Whereas, F value is 0.22 at 0.96 significance level. It interpreted that the respondents concerning income had the same behavior towards eating healthful food, whereas they did not commit to eating healthful food behavior. This result disagreed with Lee and McCleary (2012) who found that senior customers who had a positive healthful attitude were ready to spend more money on their healthful menu items. It also disagreed with Josiam and Foster (2009) who indicated that higher-income customers would eat out more often in restaurants if Nutritional Information was available. Moreover, there were no significant differences between the respondents' marital status towards eating healthful food behavior. Whereas, $F$ value is 0.96 at 0.41 significance levels. This result disagreed with Aruppillai and Phillip (2015) who found that marital status had a statistically significant influence on buying fast food in Sri Lanka.

There were significant differences among customers' education levels towards eating healthful food behavior. Whereas $F$ value is 2.32 at a 0.04 significance level. The results clarified that the significant difference existed between customers who got secondary education (mean $=9.53)$ and bachelor's degree $($ Mean=8.60) only in favor of the customers who got secondary education $(\mathrm{M}+0.92 *)$. It may be due to the customers who got secondary education relied on eating at home more than those who got a bachelor, who might eat unhealthy food at restaurants frequently. The result disagreed with Josiam and Foster (2009) who found that customers who got a college education would eat out more often in restaurants if Nutritional Information (NI) was available. The current result also disagreed with Aruppillai and Phillip (2015) who revealed that customer education level was one of the vital dimensions in the purchasing of fast-food in Sri Lanka.

\section{Table 11}

Testing hypotheses

\begin{tabular}{|l|l|l|}
\hline \multicolumn{1}{|c|}{ Hypothesis } & \multicolumn{1}{|c|}{$\begin{array}{c}\text { Adjusted } \\
\mathbf{R}^{\mathbf{2}}\end{array}$} & \multicolumn{1}{|c|}{ Result } \\
\hline $\begin{array}{l}\text { H1. Perceived health problems of eating high calories food have a } \\
\text { positive effect on the intention to eat healthy food at restaurants. }\end{array}$ & 0.13 & Supported \\
\hline $\begin{array}{l}\text { H2. Positive outcomes of eating healthful food (low calories) } \\
\text { have a positive effect on the intention to eat healthy food at } \\
\text { restaurants. }\end{array}$ & 0.14 & Supported \\
\hline $\begin{array}{l}\text { H3. Affective attitude toward eating healthful food (low calories) } \\
\text { has a positive effect on the intention to eat healthy food at } \\
\text { restaurants. }\end{array}$ & 0.16 & Supported \\
\hline $\begin{array}{l}\text { H4. Cognitive attitude toward eating healthful food (low calories) } \\
\text { has a positive effect on the intention to eat healthy food at } \\
\text { restaurants. }\end{array}$ & 0.17 & Supported \\
\hline $\begin{array}{l}\text { H5. Injunctive norms regarding eating healthful food (low } \\
\text { calories) have a positive effect on the intention to eat healthy } \\
\text { food at restaurants. }\end{array}$ & & Supported \\
\hline
\end{tabular}




\begin{tabular}{|l|l|l|}
\hline \multicolumn{1}{|c|}{ Hypothesis } & \multicolumn{1}{|c|}{$\begin{array}{c}\text { Adjusted } \\
\mathbf{R}^{\mathbf{2}}\end{array}$} & \multicolumn{1}{|c|}{ Result } \\
\hline $\begin{array}{l}\text { H6. Descriptive norms regarding eating healthful food (low } \\
\text { calories) have a positive effect on the intention to eat healthy } \\
\text { food at restaurants. }\end{array}$ & 0.22 & Supported \\
\hline $\begin{array}{l}\text { H7. Perceived behavioral control overeating healthful food (low } \\
\text { calories) has a positive effect on the intention to eat healthy food } \\
\text { at restaurants. }\end{array}$ & 0.33 & Supported \\
\hline $\begin{array}{l}\text { H8. The behavioral intention has a positive effect on eating } \\
\text { healthful food. }\end{array}$ & 0.38 & Supported \\
\hline $\begin{array}{l}\text { H9. There are statistically significant differences between respondents' } \\
\text { characteristics of eating healthy food in restaurants. }\end{array}$ & demographic \\
\hline $\begin{array}{l}\text { H9a. There are significant differences between respondents' } \\
\text { gender of eating healthy food behavior in restaurants }\end{array}$ & Sig. 0.68 & rejected \\
\hline $\begin{array}{l}\text { H9b. There are significant differences between respondents' age } \\
\text { of eating healthy food behavior in restaurants }\end{array}$ & Sig. 0.26 & rejected \\
\hline $\begin{array}{l}\text { H9c. There are significant differences between respondents' } \\
\text { income of eating healthy food behavior in restaurants }\end{array}$ & Sig. 0.96 & rejected \\
\hline $\begin{array}{l}\text { H9d. There are significant differences between respondents' } \\
\text { marital status of eating healthy food behavior in restaurants }\end{array}$ & Sig. 0.41 & rejected \\
\hline $\begin{array}{l}\text { H9e. There are significant differences between respondents' } \\
\text { education levels of eating healthy food behavior in restaurants }\end{array}$ & $\begin{array}{l}\text { Sig. } 0.04 \\
\text { M+0.92* }\end{array}$ & supported \\
\hline
\end{tabular}

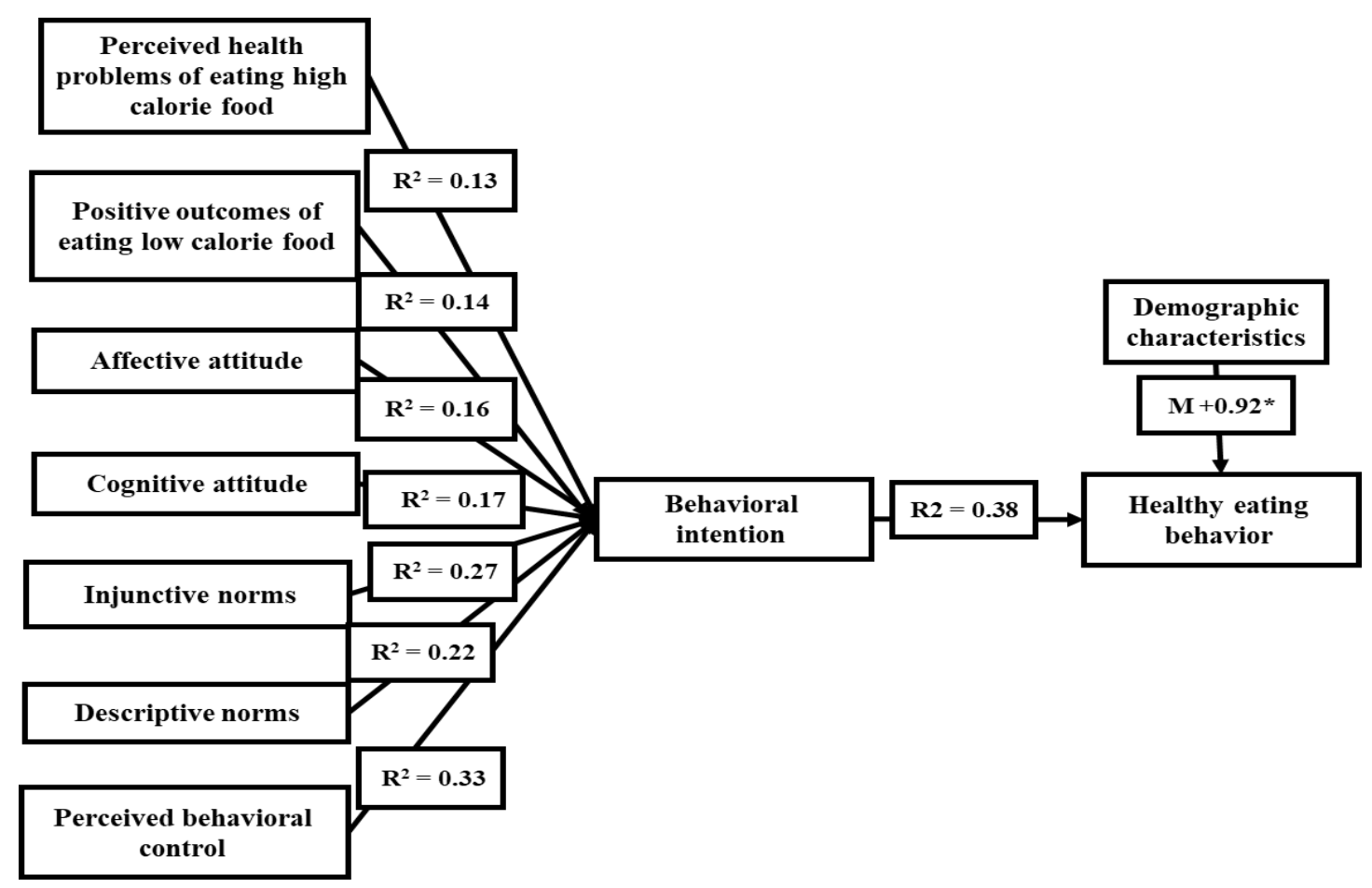

Fig. 2: Empirical model: Factors affecting restaurant customers' behaviors towards eating healthy food. 


\section{Conclusion and Recommendations}

\subsection{Conclusion}

The researcher examined the factors influencing restaurant customers' behavior toward eating healthy food. This examination was applied to the theory of planned behavior (TPB). The current research found that the respondents were overweight due to their BMI $=27.7$. Thus, they might suffer from cardiovascular diseases and deaths in the long term. The respondents preferred casual dining and fast-food restaurants more than fine dining and hotel restaurants. Almost two-thirds of the respondents spent less than $10 \%$ to $20 \%$ of their income to eat at restaurants. Moreover, more than half of them had a shortage of healthy food definition, which reflected in their selection of unhealthy foods. A low percent of the respondents often or always used menu calorie labeling if it found in the menus. It indicated low perceived awareness among them about the importance of using menu calorie labeling. A low percent of the respondents had healthful eating behavior, who selected healthful food at restaurants daily or every two or three days.

The respondents did not select healthy food due to the restaurants did not offer healthy food; the respondents were not interested in healthy food; healthy foods were too expensive. In contrast, there was a ratio of the respondents was attracted to healthful food due to its nutritional value; low calories; attractive prices. It might be due to their health status or diet. Moreover, the most restaurants did not add healthful food to their menus. However, fine dining and hotel restaurants were interested in offering healthful food more than casual dining and fast-food restaurants. Furthermore, most different restaurants did not apply the menu calorie labeling, had no aware of its importance to conserve customers' health from diseases and support the restaurant's image towards customers.

Furthermore, averages of the scale constructs assured leakage of customers' intentions; behavior; their influencing factors towards eating healthful food at restaurants. It may lead to obesity and related diseases to customers in the long term. In contrast, there was a significant correlation between the constructs. Moreover, all scale constructs influenced on predicting customers' behavioral intentions towards eating healthful food in restaurants. Customers' behavioral intentions influenced predicting their behavior towards eating healthful food. There were only significant differences between respondents' educational levels. The respondents who got secondary school were better than those who got bachelor degree towards eating healthy food behavior.

\subsection{Recommendations}

\subsubsection{Recommendations for restaurant customers}

- Customers should increase their knowledge; positive attitude; intentions and behavior towards eating healthful food at restaurants. They should read nutrition and public health books; magazines; reports; web sites, or watch TV programs; internet videos.

- Customers should decrease the frequencies of eating in different restaurants to reach once or twice a month. It decreases calories, trans-fat, and sodium intake. 
- Customers should train themselves to select balanced healthy meals daily. It assists them to control their perceived behavior and choose healthy food in restaurants.

- Customers should assist and convince their children; families; friends to improve their healthy eating behavior by choosing healthy; hedonic; low calories, fat, and sodium dishes in restaurants.

- Customers should have healthy eating attitude; intention; behavior to fight obesity. Therefore, they should pressure restaurants; food manufactures; government to change their practices.

- Customers should establish an agency aimed to conserve public health; increase people's healthy eating behavior. This agency should cooperate with specialized authorities to obligate restaurants providing healthy food and posting menu calorie labeling.

\subsubsection{Recommendations for restaurant managers}

- Restaurants managers should offer healthy cooked; hedonic; balanced foods when planning menus. These foods provide customers with a recommended daily allowance; prevent them from obesity diseases.

- The managers should post menu calorie labeling for each item on the menu. These labels should easily accessible; readable; easy to use for anyone who visits restaurants.

- Restaurant managers should incentive customers to select healthy food from the menu. They should provide toys to children; fruit plates; natural juices; discount of the total check; coupons for free meals; attractive prices; free tickets to cinema or park.

- The managers should cooperate with governmental authorities to provide brochures; posters; videos; TV programs; training programs for learning; improving customers' healthy eating behavior.

- They should decrease high calories; fat; salt foods from the menu; cook food with healthy; attractive methods to conserve customers' health.

\subsubsection{Recommendations for governmental authorities}

- The governmental authorities should effectively monitor restaurants to obligate them to offer healthy foods on the menu; decrease unhealthy foods; post menu calorie labeling.

- They should update health and nutrition laws to obligate restaurants that have 10 branch or more to post menu calorie labeling in the menus; offer healthy food on the menu.

- They can release health campaign aimed to improve restaurant customers' culture; knowledge; attitude; intention; behavior towards eating healthy food. It can be achieved through different media means.

- Health campaign should involve best practices and training methods for improving customers' healthful eating behavior when visiting restaurants.

- The authorities can coordinate with nongovernmental associations; companies; businessmen to undertake health campaigns. 
- The authorities can also obligate the Ministries of Education and High Education to prepare curricula for students in schools and universities to educate them on how to develop their healthy eating behavior.

\section{Limitation and future research}

The researcher applied this research during the period between February and May 2020 in Minia district restaurants in Minia Governorate. Furthermore, investigating the variables influencing guest behavior towards eating healthy food will be required to apply to guests who visit five and four star hotels in Cairo, Red Sea, and Nile cruise restaurants. There is a need to examine other influencing variables on guest behavior, or compare among guest nationalities towards healthy eating behavior, or apply other theories.

\section{References}

- Ajzen, I. (1991). The Theory of Planned Behavior. Organizational Behavior and Human Decision Processes, 50 (2), 179-211.

- Ajzen, I. (2002). Perceived behavioral control, self-efficacy, locus of control, and the theory of planned Behavior1. Journal of Applied Social Psychology, 32 (4), $665-683$.

- Aruppillai, T., and Phillip, P. M. G. (2015). An Analysis of Consumers' Buying Behavior and Its Determinants of Fast Food in Sri Lanka. International Journal of Economics and Finance, 7 (9), 112-119.

- Bagozzi, R. P., Wong, N., Abe, S., and Bergami, M. (2000). Cultural and situational contingencies and the theory of reasoned action: application to fast food restaurant consumption. Journal of Consumer Psychology, 9 (2), 97-106.

- Ball, K., Jeffery, R. W., Abbot, G., McNaughton, S. A., and Crawford, D. (2010). Is healthy behavior contagious: association of social norms with physical activity and healthy eating? International Journal of Behavioral Nutrition and Physical Activity, 7 (86), 1-9.

- Bartlett, J. E., Kotrlik, J. W., and Higgins, C. C. (2001). Organizational Research: Determining Appropriate Sample Size in Survey Research. Learning and Performance Journal, 19, 43-50.

- Benelam, B. (2009).calories in the menu. Nutrition Bulletin, 34 (3), 289-90.

- Bishop, A. C., Baker, G. R., Boyle, T. A., and MacKinnon, N. J. (2015). Using the Health Belief Model to explain patient involvement in patient safety. Health Expectations, 18(6), 3019-3033.

- Brissette, I., Lowenfels, A., Noble, C., and Spicer, D. (2013). Predictors of Total Calories Purchased at Fast-food Restaurants: Restaurant Characteristics, Calorie Awareness, and Use of Calorie Information. Journal of Nutrition Education and Behavior, 45 (5), 404-411.

- Central Agency for Public Mobilization and Statistics of Egypt. (2017). Estimate the number of the Egyptian population in the departments and centers according to 
the type and place of residence. Available at https://capmas.gov.eg/Admin/Pages\%20Files/201871611358gov.pdf, Retrieved April 132020.

- Chen, J. S., Legrend, W., and Sloan, P. (2006). Factors influencing healthy meal choice in Germany. Journal of Tourism, 54 (4), 315-322.

- Cheng, S., Lam, T., and Hsu, C.H.C. (2005). Testing the sufficiency of the theory of planned behavior: a case of customer dissatisfaction responses in restaurants. International Journal of Hospitality Management, 24 (4), 475-492.

- Dean, M., Raats, M. M., and Shepherd, R. (2008). Moral concerns and consumer choice of fresh and processed organic Foods1. Journal of Applied Social Psychology, 38 (8), 2088-2107.

- Dunn, K. I., Mohr, P., Wilson, C. J., and Wittert, G. A. (2011). Determinants of fast food consumption. An application of the theory of planned behavior. Appetite, 57 (2), 349-357.

- Gallicano, R., Blomme, R., and Rheede, A. V. (2012). Consumer Response to Nutrition Information Menu Labeling in Full-Service Restaurants: Making the Healthy Choice. Advances in Hospitality and Leisure, 8, 109-125.

- Hasbullah, N., Mahajar, A. J., and Salleh, M. I. (2014). A Conceptual Framework of Extending the Theory of Planned Behavior: The Role of Service Quality and Trust in the Consumer Cooperatives. International Journal of Business and Social Science, 5 (12), 142-148.

- Hollands, S., Campbell, M. K., Gilliland, J., and Sarma, S., (2014). Association between neighbourhood fast-food and full-service restaurant density and body mass index: A cross-sectional study of Canadian adults. Canadian Journal of Public Health / Revue Canadienne de Santé Publique, 105 (3), e172-e178.

- Jeong, J., and Ham, S. (2018). Application of the Health Belief Model to customers' use of menu labels in restaurants. Appetite, 123: 208-215.

- Jeong, E., Jang, S., Behnke, C., Anderson, J., and Day, J. (2019). A scale for restaurant customers' healthy menu choices: individual and environmental factors. International Journal of Contemporary Hospitality Management, 31 (1), 217-246.

- Josiam, B., and Foster, C. (2009). Nutritional information on restaurant menus: Who cares and why restaurateurs should bother. International Journal of Contemporary Hospitality Management, 21 (7), 876-891.

- Jun, J., and Arendt, S. W. (2016). Understanding healthy eating behaviors at casual dining restaurants using the extended theory of planned behavior. International Journal of Hospitality Management, 53, 106-115.

- Jun, J., Kang, J., and Arendt, S. W. (2014). The Effects of Health Value on Healthful Food Selection Intention at Restaurants: Considering the Role of Attitudes toward Taste and Healthfulness of Healthful Foods. International Journal of Hospitality Management, 42, 85-91. 
- Kang, J., Jun, J., and Arendt, S. W. (2015). Understanding customers' healthy food choices at casual dining restaurants: Using the Value-Attitude-Behavior model. International Journal of Hospitality Management, 48, 12-21.

- Kassem, N. O., Lee, J. W., Modeste, N. N., and Johnson, P. K. (2003). Understanding soft drink consumption among female adolescents using the Theory of Planned Behavior. Health Education Research, 18 (3), 278-291.

- Kim. E., Ham, S., Yang, I. S., and Choi, J. G. (2013). The roles of attitude, subjective norm, and perceived behavioral control in the formation of consumers' behavioral intentions to read menu labels in the restaurant industry. International Journal of Hospitality Management, 35, 203-213.

- Kim, K., Reicks, M., and Sjoberg, S. (2003). Applying the theory of planned behavior to predict dairy product consumption by older adults. Journal of Nutrition Education and Behavior, 35 (6), 294-301.

- Lally, P., Bartle, N., and Wardle, J. (2011). Social norms and diet in adolescents. Appetite, 57 (3), 623-627.

- LaMorte, W. W. (2019). The Theory of Planned Behavior. Available at http://sphweb.bumc.bu.edu/otlt/MPH-

Modules/SB/BehavioralChangeTheories/BehavioralChangeTheories3.html, Retrieved April 192020.

- Lawton, R., Conner, M., and McEachan, R. (2009). Desire or reason: predicting health behaviors from affective and cognitive attitudes. Health Psychology, 28 (1), $56-65$.

- Lee, S. T., and McCleary, K. (2012). The Relationship between Perceived Health, Health Attitude, and Healthy Offerings for Seniors at Family Restaurants. Cornell Hospitality Quarterly, 54(3), 262-273.

- Manning, M. (2009). The effects of subjective norms on behavior in the theory of planned behavior: the meta-analysis. British Journal of Social Psychology. 48 (4), 649-705.

- Massachusetts Medical Society. (2017). Health Effects of Overweight and Obesity in 195 Countries over 25 Years. The New England Journal of Medicine, 377 (1), $13-27$.

- Norman, R. (1975). Affective-cognitive consistency, attitudes, conformity, and behavior. Journal of Personality and Social Psychology, 32 (1), 83-91.

- Onyango, F. E. V., and Wasike, K. C. (2018). Healthy Eating Products and Customer Outcomes in Restaurants. Journal of Tourism and Management Research, 3(1), 200-212.

- Nunnally, J. C. (1978) Psychometric Theory. New York. McGraw-Hill, USA.

- Park, D. Y. (2011). Utilizing the Health Belief Model to predicting female middle school students' behavioral intention of weight reduction by weight status. Nutrition Research and Practice, 5 (4), 337-348. 
- Pawlak, R., and Malinauskas, B. (2008). The use of the theory of planned behavior to assess predictors of intention to eat fruits among 9th-grade students attending two public high schools in eastern North Carolina. Family and Consumer Sciences Research Journal, 37 (1), 16-26.

- Pawlak, R., Malinauskas, B., and Rivera, D. (2009). Predicting intentions to eat a healthful diet by college baseball players: applying the theory of planned behavior. Journal of Nutrition Education and Behavior, 41 (5), 334-339.

- Payne, N., Jones, F., and Harris, P. R. (2004). The role of perceived need within the theory of planned behavior: a comparison of exercise and healthy eating. British Journal of Health Psychology, 9 (4), 489-504.

- Rah, J. H., Hasler, C. M., Painter, J. E., and Chapman-Novakofski, K.M. (2004). Applying the theory of planned behavior to women's behavioral attitudes on and consumption of soy products. Journal of Nutrition Education Behavior, 36 (5), 238-244.

- Rimal, R. N., and Real, K. (2005). How behaviors are influenced by perceived norms: a test of the theory of normative social behavior. Communication research, 32 (3), 389-414.

- Rivis, A., and Sheeran, P. (2003). Descriptive norms as an additional predictor in the theory of planned behavior: a meta-analysis. Current Psychology, 22, 218-233.

- Rizkallah, E. G. and Feiler, K. (2013). The Effects Of Calorie Count Display On Consumer Eating Behavior: Would It Solve The Obesity Problem? An Empirical Perspective. American Journal of Health Sciences, 4 (2), 79-88.

- Saba, A., Vassallo, M., Shepherd, R., Lampila, P., Arvola, A., Dean, M., Winkelmann, M., Claupein, E., and Lähteenmäki, L. (2010). Country-wise differences in perception of health-related messages in cereal- based food products. Food Quality and Preference, 21, 385-393.

- Saksena, M. J., Okrent, A. M., Anekwe, T. D., Cho, C., Dicken, C., Effland, A., et al., (2018). America's Eating Habits: Food Away From Home, EIB-196, Available at https://www.ers.usda.gov/webdocs/publications/90228/eib-196.pdf, Retrieved March 242020.

- Sjoberg, S., Kim, K., and Reicks, M. (2004). Applying the theory of planned behavior to fruit and vegetable consumption by older adults. Journal of Nutrition for the Elderly, 23(4), 35-46.

- Stewart, H., Blisard, N., and Jolliffe, D. (2006). Let's Eat Out Americans Weigh Taste, Convenience, and Nutrition. Available at https://ageconsearch.umn.edu/record/59411/files/eib19.pdf, Retrieved March 24 2020.

- Story, M., Kaphingst, K. M., O’Brien, R. R., and Glanz, K. (2008). Creating Healthy Food and Eating Environments: Policy and Environmental Approaches. Annual Review of Public Health, 29, 253-72. 
- Sualakamala, S., and Huffman, L. (2010). Value negotiation for healthy food selection in restaurants. Journal of Culinary. Science. Technology, 8 (4), 242-256.

- Taherdoost, H. (2017). Determining Sample Size; How to Calculate Survey Sample Size. Available at https://www.researchgate.net/search.Search.html?type=publication\&query=Determ ining\%20Sample\%20Size;\%20How\%20to\%20Calculate\%20Survey, Retrieved April 152020.

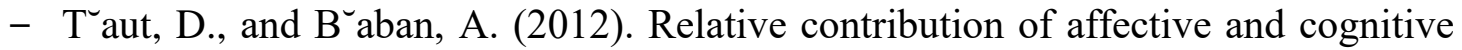
attitudes in predicting physical activity. Cognition Brain Behavior. Interdisciplinary Journal, 16, 403-421.

- Tommasetti, A., Singer, P., Troisi, O., and Maione, G. (2018). Extended Theory of Planned Behavior (ETPB): Investigating Customers' Perception of Restaurants' Sustainability by Testing a Structural Equation Model. Sustainability, 10: 1-21.

- Tourism office in Minia governorate. (2020). Number of restaurants in Minia Governorate. (Brochure). Minia.

- Tuu, H.H., Olsen, S.O., Thao, D.T., and Anh, N.T.K. (2008). The role of norms in explaining attitudes, intention and consumption of a common food (fish) in Vietnam. Appetite, 51 (3), 546-551.

- Unilever's Food Solutions. (2011). World menu report global research findings 2011. Available at http://www.unileverfoodsolutions.com/company/mediacenter/world-menu-report, Retrieved March 142020.

- Unilever's Food Solutions Division. (2012). World Menu Report Global Research Findings 2012. Available at https://www.unilever.com/Images/wmr-3-seductivenutrition_tcm13-387347_tcm244-409864_en.pdf, Retrieved March 152020.

- Varela, P., Ares, G., Giménez, A., and Gámbaro, A. (2010). Influence of brand information on customers' expectations and liking of powered drinks in central location tests. Food Quality and Preference, 21 (7), 873-880.

- World Bank. (2017). Egyptian National Railways Restructuring Project (ENRRP) $3^{\text {rd }}$ Public Consultation Sohag, 11-October-2017. Available at http://documents.worldbank.org/curated/en/574531511419639286/pdf/SFG3808V2-EA-P101103-Box405311B-PUBLIC-Disclosed-11-23-2017.pdf, Retrieved June 22020.

- World Health Organization. (2020). Obesity. Available at http://www.emro.who.int/health-topics/obesity/, Retrieved May 292020.

- Zhang, K. (2018). Theory of Planned Behavior: Origins, Development and Future Direction. International Journal of Humanities and Social Science Invention, 7 (5), 76-83. 


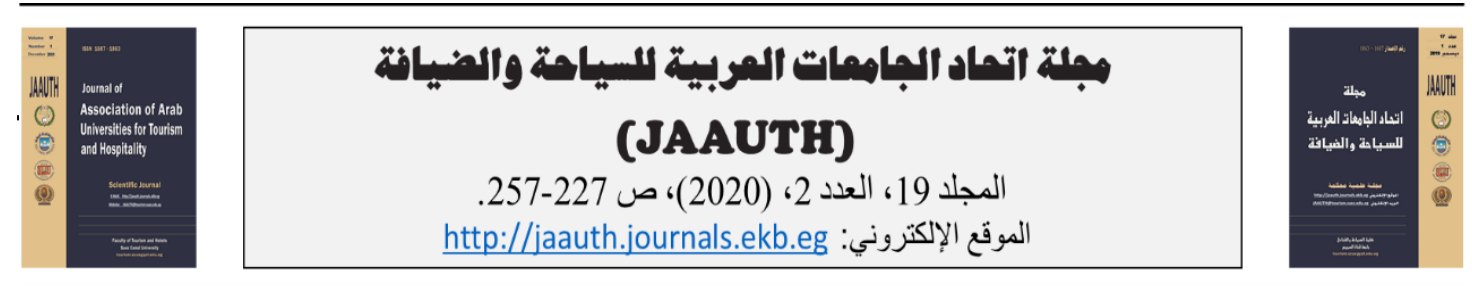

العوامل المؤثرة على سلوك العملاء تجاه تناول الأطعمة الصحية في المطاعم في محافظة المنيا بمصر

مصطفى محمود محمد حسين

قسم إدارة الفنادق، كلية السياحة والفنادق، جامعة المنيا، المنيا، مصر مردين

\begin{tabular}{|c|c|}
\hline & منومات الرجالة \\
\hline 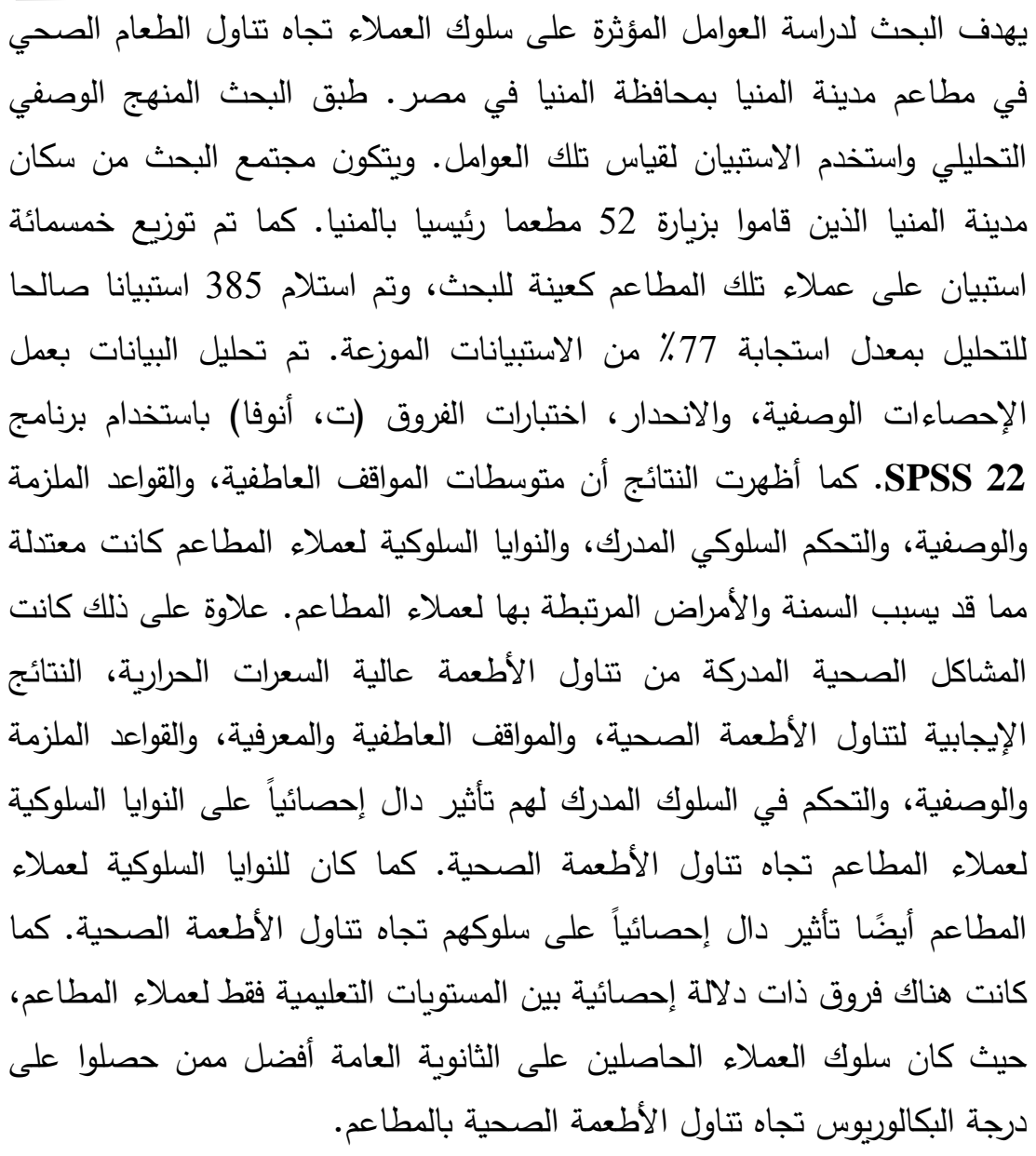 & الطاقات السعرات الحرارية؛ السلوكة الصحية؛ نظرية \\
\hline
\end{tabular}

